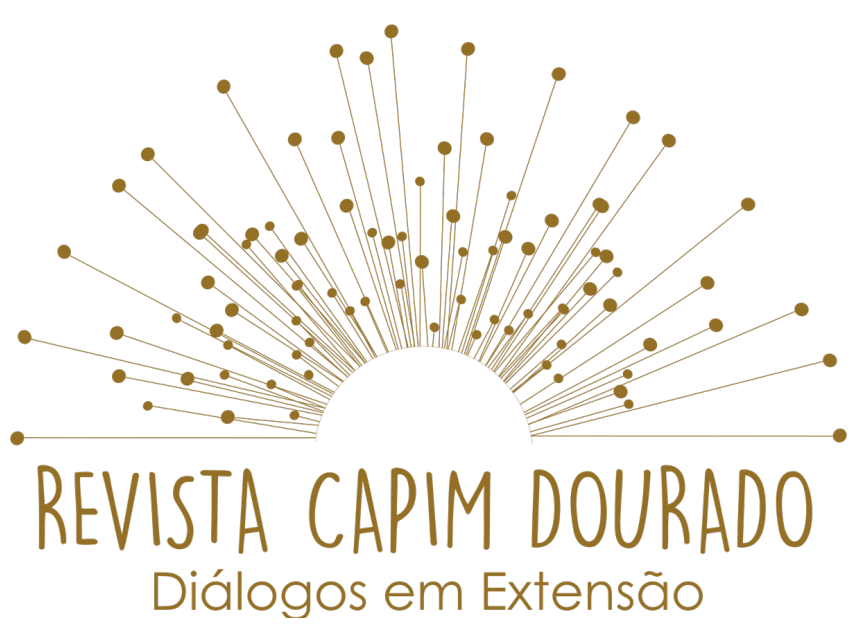

ISSN n² 2595-7341

Vol. 3, n. 2, Maio-Agosto, 2020

DOI: http://dx.doi.org/10.20873/uft.2595-7341.2020v3n2p47

\title{
PSICOLOGIA E EDUCAÇÃO NA PROMOÇÃO DE BEM-ESTAR PSICOSSOCIAL EM TEMPOS DE PANDEMIA: Relato de uma prática de extensão universitária
}

PSYCHOLOGY AND EDUCATION IN THE PROMOTION OF PSYCHOSOCIAL WELFARE IN PANDEMIC TIMES: Report of a university extension practice

PSICOLOGÍA Y EDUCACIÓN EN LA PROMOCIÓN DEL BIENESTAR PSICOSOCIAL EN TIEMPOS DE PANDEMIA: Informe de una práctica de extensión universitária

\author{
Ladislau Ribeiro Do Nascimento ${ }^{1}$ \\ Jayana Milhomem de Souza² \\ Maria Santana Ferreira dos Santos Milhomem ${ }^{3}$ \\ Maria de Lourdes Leôncio Macedo4
}

\section{RESUMO}

Este artigo relata uma prática de extensão universitária voltada para promover saúde mental e bem-estar psicossocial no contexto da pandemia gerada pela Covid-19. Elegemos como público-alvo professores e estudantes de escolas públicas do Estado do Tocantins. Realizamos palestras e sensibilizações por meio

\footnotetext{
${ }^{1}$ Docente do curso de Licenciatura em Psicologia da Universidade Federal do Tocantins (UFT), Campus Miracema, Tocantins, ladislaunascimento@uft.edu.br.

${ }^{2}$ Discente do curso de Licenciatura em ao em Psicologia da Universidade Federal do Tocantins (UFT), Tocantins, jayanamilhomem@gmail.com.

${ }^{3}$ Docente do curso de Licenciatura em da Universidade Federal do Tocantins (UFT), Campus Palmas, Tocantins, msfsantos@uft.edu.br.

${ }^{4}$ Docente do curso de Licenciatura em História da Universidade Estadual de Maringá, UEM, Brasil, do Fundamental e Médio de História, Palmas, Tocantins, malutocantins@gmail.com.
} 


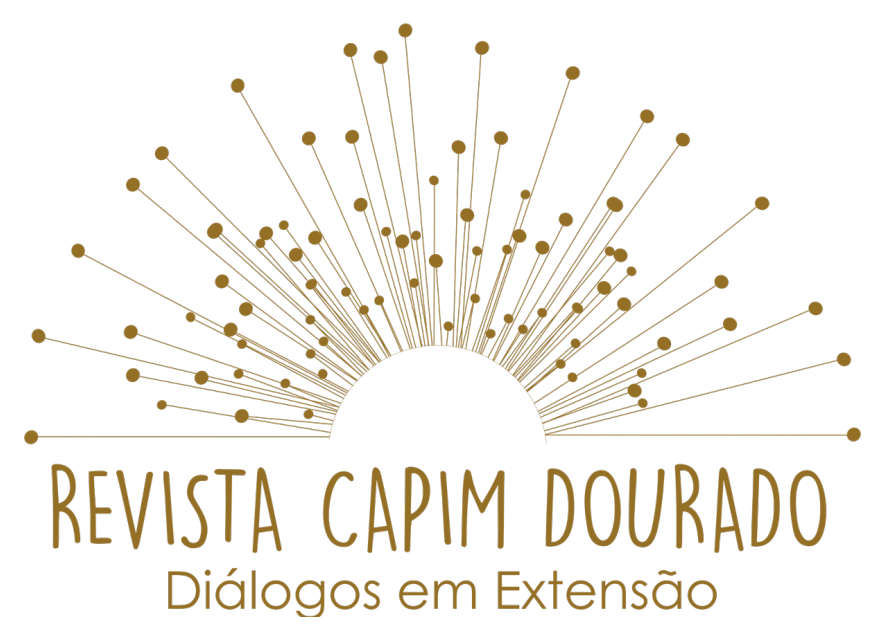

ISSN n² 2595-7341

Vol. 3, n. 2, Maio-Agosto, 2020

DOI: http://dx.doi.org/10.20873/uft.2595-7341.2020v3n2p47

do uso de Tecnologias da Informação e da Comunicação (TIC). Além disso, elaboramos materiais instrucionais sobre o tema em foco. $O$ trabalho resultou em promoção de bem-estar psicossocial e desenvolvimento de habilidades socioemocionais.

PALAVRAS-CHAVE: Covid-19; Intervenção Psicossocial; Educação Pública.

\section{ABSTRACT}

This article reports on a community outreach practice aimed at promoting mental health and psychosocial well-being in the context of the pandemic generated by Covid-19. We elected as target audience teachers and students from public schools in the State of Tocantins. We deliver lectures, sensitizations and short courses through virtual platforms. In addition, we prepared instructional materials on the topic at hand. The work resulted in the promotion of psychosocial wellbeing and the development of socio-emotional skills.

KEYWORDS: Covid-19; Psychosocial Intervention; Public education.

\section{RESUMEN}

Este artículo informa sobre una práctica de extensión universitaria destinada a promover la salud mental y el bienestar psicosocial en el contexto de la pandemia generada por Covid-19. Elegimos como público objetivo a maestros y estudiantes de escuelas públicas en el estado de Tocantins. Realizamos conferencias y sensibilizaciones mediante el uso de las Tecnologías de la Información y la Comunicación (TIC). Además, preparamos materiales de instrucción sobre el tema en cuestión. El trabajo resultó en la promoción del bienestar psicosocial y el desarrollo de habilidades socioemocionales.

PALABRAS CLAVE: Covid-19; Intervención psicosocial; Educacion publica. 


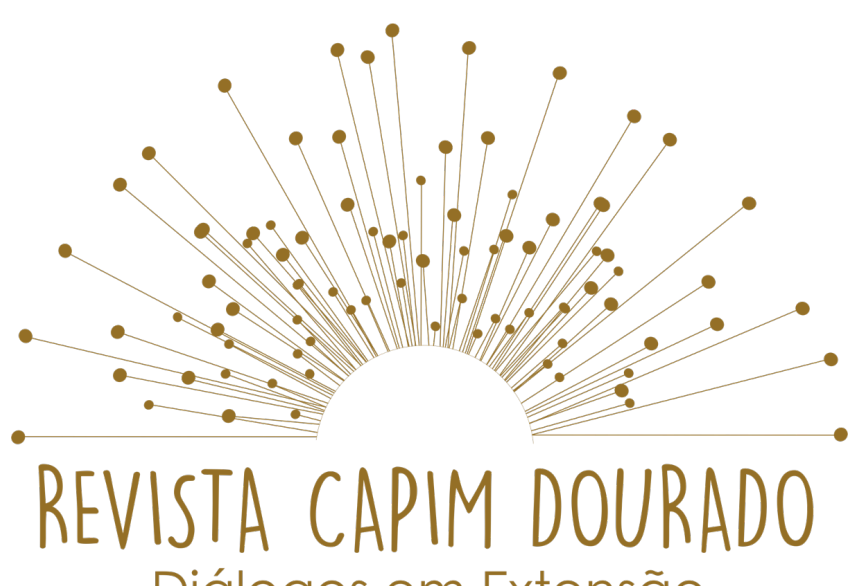

\section{Diálogos em Extensão}

ISSN n² 2595-7341

Vol. 3, n. 2, Maio-Agosto, 2020

DOI: http://dx.doi.org/10.20873/uft.2595-7341.2020v3n2p47

\section{INTRODUÇÃO}

No final de 2019, a Organização Mundial de Saúde (OMS) trouxe ao público geral uma notícia sobre o novo coronavírus (Severe Acute Respiratory Syndrome Coronavirus 2 - SARS-Cov2), denominado de COVID-19, que passaria a ser tratado como um problema de saúde pública de importância internacional no fim de janeiro do ano seguinte (OMS, 2020). Inicialmente reportado em Wuhan, na China (WANG et al., 2020; XIAO, 2020), evoluiu rapidamente e se espalhou para todos os continentes como uma pandemia. (WHO, 2020).

As tensões provocadas a partir do início do ano de 2020 no Brasil, em decorrência desta pandemia, provocaram reações jamais vistas. Centenas de países no mundo adotaram medidas de proteção como distanciamento social, isolamento e quarentena. Houve também a construção de hospitais de campanha e a aquisição de equipamentos de proteção individual (EPI), além de capacitações para profissionais de saúde e para cidadãos de um modo geral (BRASIL, 2020a).

A crise gerada pela pandemia está produzindo adoecimento mental e sofrimento psicossocial em milhares de pessoas ao redor do mundo. De acordo com informações do Ministério da Saúde (BRASIL, 2020b), estima-se que um terço ou até mesmo a metade da população exposta a uma pandemia manifeste sintomas de adoecimento mental. Medo, angústia, depressão, estresse, transtornos do pânico, ideações suicidas, suicídios, raiva, insônia, abuso de álcool e outras drogas aparecem como as principais consequências do mal-estar neste momento de calamidade (DUAN; ZHU, 2020). 


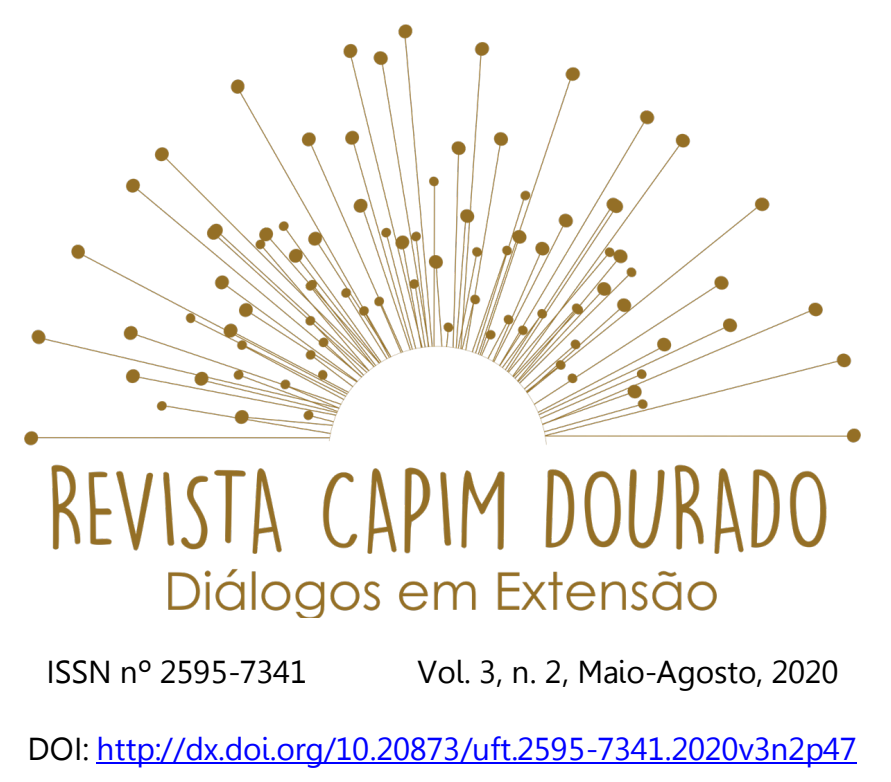

No contexto educacional houve a suspensão de atividades de ensino em todos os níveis de formação. Mais especificamente nas instituições de Educação Básica da rede pública do Estado do Tocantins, adotou-se como medida protetiva a suspensão de todas as atividades escolares. Deste modo, professores e estudantes deixaram de frequentar os espaços escolares e passaram a lidar com as demandas de um novo contexto. No caso dos professores, realizaram-se treinamentos, reuniões e cursos sobre temáticas relacionadas à educação. Os estudantes, por sua vez, não participaram de quaisquer atividades vinculadas à formação educacional.

A partir de Junho de 2020, todavia, lideranças vinculadas ao governo estadual tornaram pública a intenção de retomar as atividades escolares. $\mathrm{Na}$ ocasião, representantes da Secretaria da Educação, Juventude e Esportes (SEDUC) buscaram parcerias a fim de viabilizarem o retorno às aulas. Naquele contexto, a partir de um acordo de Cooperação entre Universidade Federal do Tocantins (UFT) e Secretaria de Estado da Educação, Juventude e Esportes do Estado do Tocantins (SEDUC-TO), desenvolvemos uma proposta de extensão universitária que teve como objetivo promover saúde mental e bem-estar psicossocial em professores e estudantes da Educação Básica vinculados ao sistema público da rede estadual de ensino do Estado do Tocantins.

As ações foram planejadas por meio de um projeto apoiado pela PróReitoria de Extensão, Cultura e Assuntos Comunitários (PROEX) da Universidade Federal do Tocantins (UFT), intitulado, Psicologia e Educação no enfrentamento do sofrimento psicossocial em tempos de pandemia. Vale observar que, este relato considera a execução do primeiro módulo do projeto. Relatamos as ações 


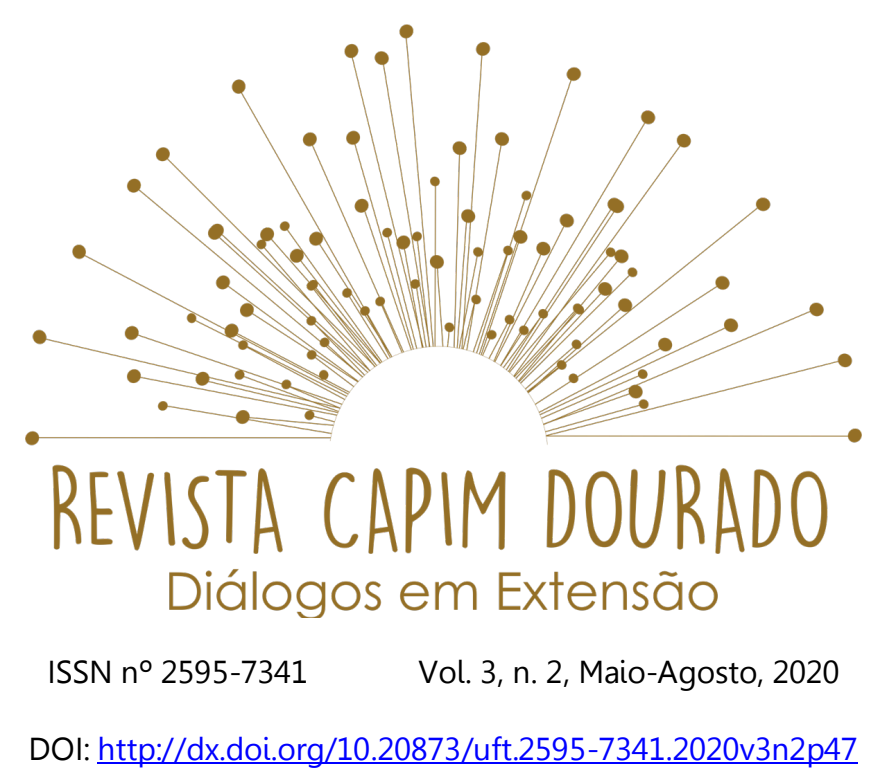

realizadas entre maio e junho de 2020. O término da ação está previsto para dezembro de 2020.

De maneira específica, buscamos (1) colaborar no fortalecimento da parceria entre UFT e SEDUC-TO por meio de uma atividade de Extensão Universitária; (2) orientar o público sobre como enfrentar o sofrimento psicossocial em meio à incerteza gerada no contexto da pandemia; (3) promover bem-estar psicossocial; (4) acolher casos de adoecimento mental e sofrimento psicossocial; (5) instruir professores e estudantes para a realização de encaminhamentos adequados em casos de adoecimento mental; (6) conscientizar professores e estudantes sobre o papel de cada um no enfrentamento do sofrimento psicossocial; (7) melhorar a Qualidade de Vida (QV) de professores e estudantes da Educação Básica.

\section{MÉTODO}

Utilizamos a abordagem psicossocial (NEIVA, 2010) como estratégia para acolher demandas psicossociais do público-alvo. Além disso, promovemos atividades psicoeducacionais destinadas para a conscientização dos participantes acerca do papel de cada um perante os desafios impostos pela crise associada com a Covid-19. Nesta perspectiva, portanto, estruturamos a proposta em duas dimensões: (a) psicoeducativa e (b) psicossocial.

A dimensão psicoeducativa incluiu elaboração de recursos instrucionais, baseados em evidências científicas, para serem disponibilizados em linguagem acessível ao público através de canais de comunicação da SEDUC-TO, tais como: portal institucional, ambiente virtual de aprendizagem (AVA) e contas oficiais da 


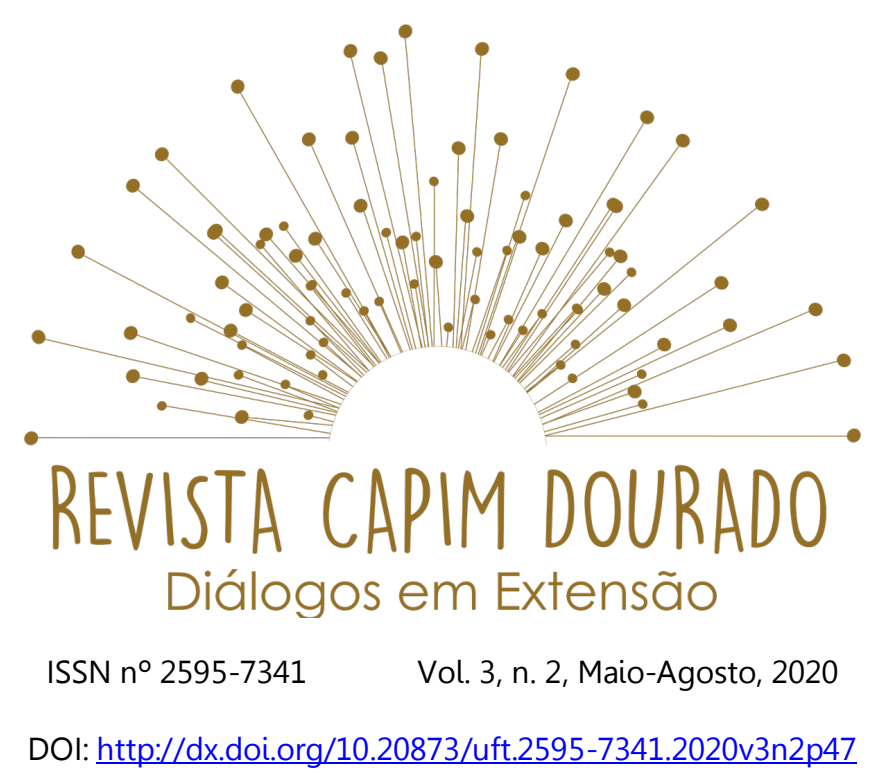

Secretaria no Facebook e Instagram. Buscou-se promover processos de ensino e de aprendizagem em uma perspectiva social e histórica, tendo como referência o sociointeracionismo (VYGOTSKY, 1988).

A dimensão psicossocial, por sua vez, abrangeu a criação de um canal de acolhimento para professores, e estudantes da Educação Básica, como estratégia para fortalecer a subjetividade dos participantes em um movimento de enfrentamento do sofrimento psicossocial atrelado ao contexto de pandemia. Esta dimensão incluiu atividades como, palestras e sensibilizações destinados ao público-alvo através de plataformas virtuais.

\section{RELATO DA EXPERIÊNCIA}

Inicialmente os responsáveis pelas instituições assinaram um termo de cooperação que firmou legalmente a parceria entre a SEDUC-TO e a PROEX/UFT a partir do projeto aqui relatado. O primeiro evento fruto desta parceria foi uma live destinada ao lançamento do programa do Governo do Tocantins, denominado "Olhar Atento", que agrupa uma série de atividades voltadas aos cuidados com a saúde psicossocial de toda a comunidade escolar.

O evento foi transmitido pelo canal TV SEDUC - TO, vinculado ao YouTube. Participaram do evento, a secretária de educação do estado, a diretora de um instituto parceiro da Secretaria, responsável por um projeto destinado ao desenvolvimento de habilidades socioemocionais em professores e alunos, e o coordenador desta ação, que apresentou e divulgou a proposta cujos resultados parciais são reportados neste artigo. 


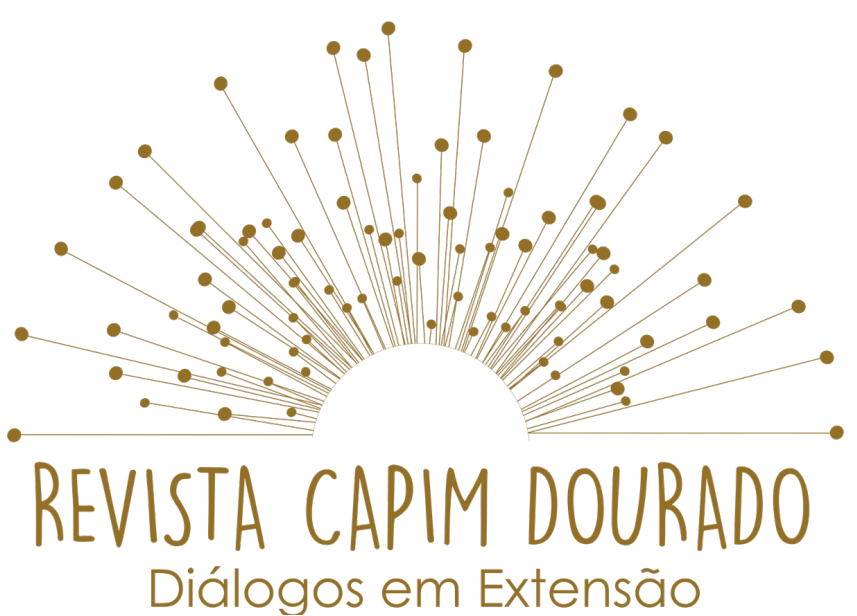

ISSN n² 2595-7341

Vol. 3, n. 2, Maio-Agosto, 2020

DOI: http://dx.doi.org/10.20873/uft.2595-7341.2020v3n2p47

O programa "Olhar Atento" (PORTAL TOCANTINS, 2020) está voltado ao apoio e cuidado emocional a educadores e estudantes da rede estadual, e por isso aquele momento foi dedicado especialmente aos docentes e discentes da rede pública de ensino, contando com mais de dois mil participantes no momento da transmissão. Uma semana após o evento o vídeo, armazenado no no canal do YouTube, possuía mais de dez mil visualizações.

A partir da inauguração da parceria interinstitucional, a equipe, composta pelos autores deste relato, iniciou a produção dos materiais psicoeducativos e desenvolveu as práticas de intervenção psicossocial, conforme exposto a seguir.

\section{Elaboração e divulgação de materiais instrucionais}

Em um primeiro momento, elaborou-se uma sequência de imagens informativas (encarte), adaptadas para publicação em qualquer rede social ou canal de comunicação, com o objetivo de transmitir informações sobre o manejo do sofrimento psicossocial produzido em face à pandemia (vide quadro a seguir). 


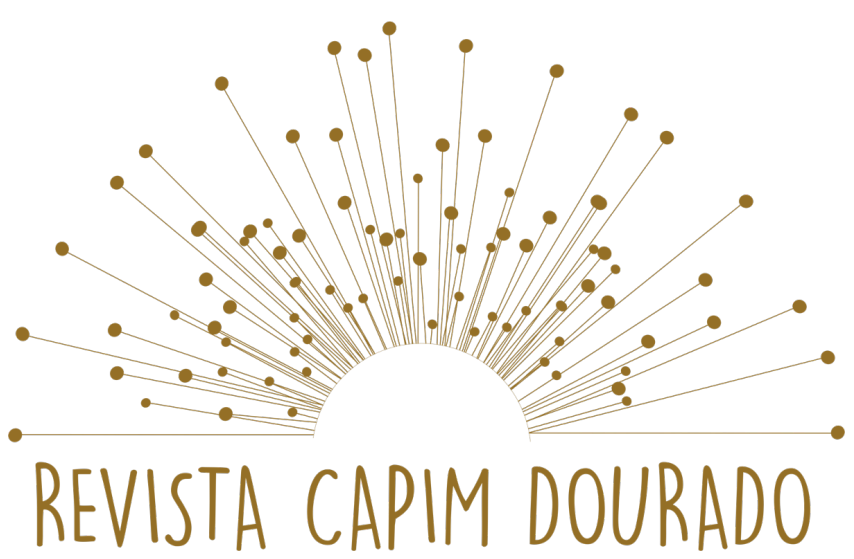

Diálogos em Extensão

ISSN n² 2595-7341

Vol. 3, n. 2, Maio-Agosto, 2020

DOI: http://dx.doi.org/10.20873/uft.2595-7341.2020v3n2p47

Quadro n.1: Recomendações para a promoção de bem-estar psicossocial.

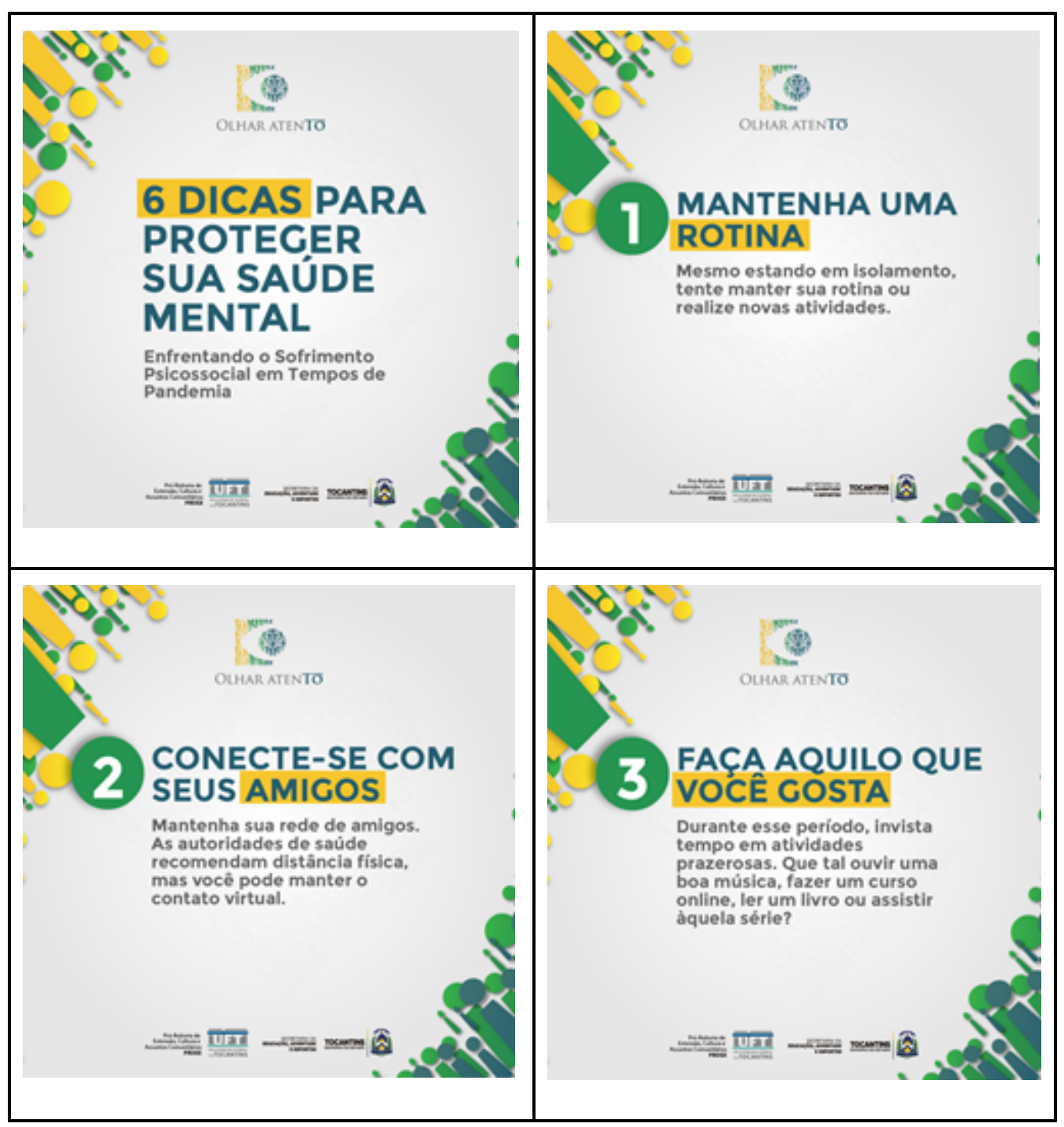




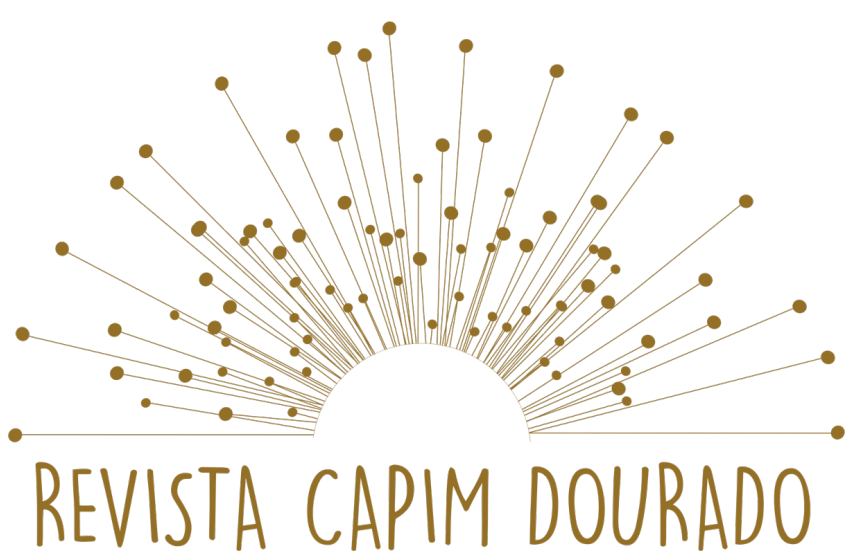

Diálogos em Extensão

ISSN n² 2595-7341

Vol. 3, n. 2, Maio-Agosto, 2020

DOI: http://dx.doi.org/10.20873/uft.2595-7341.2020v3n2p47

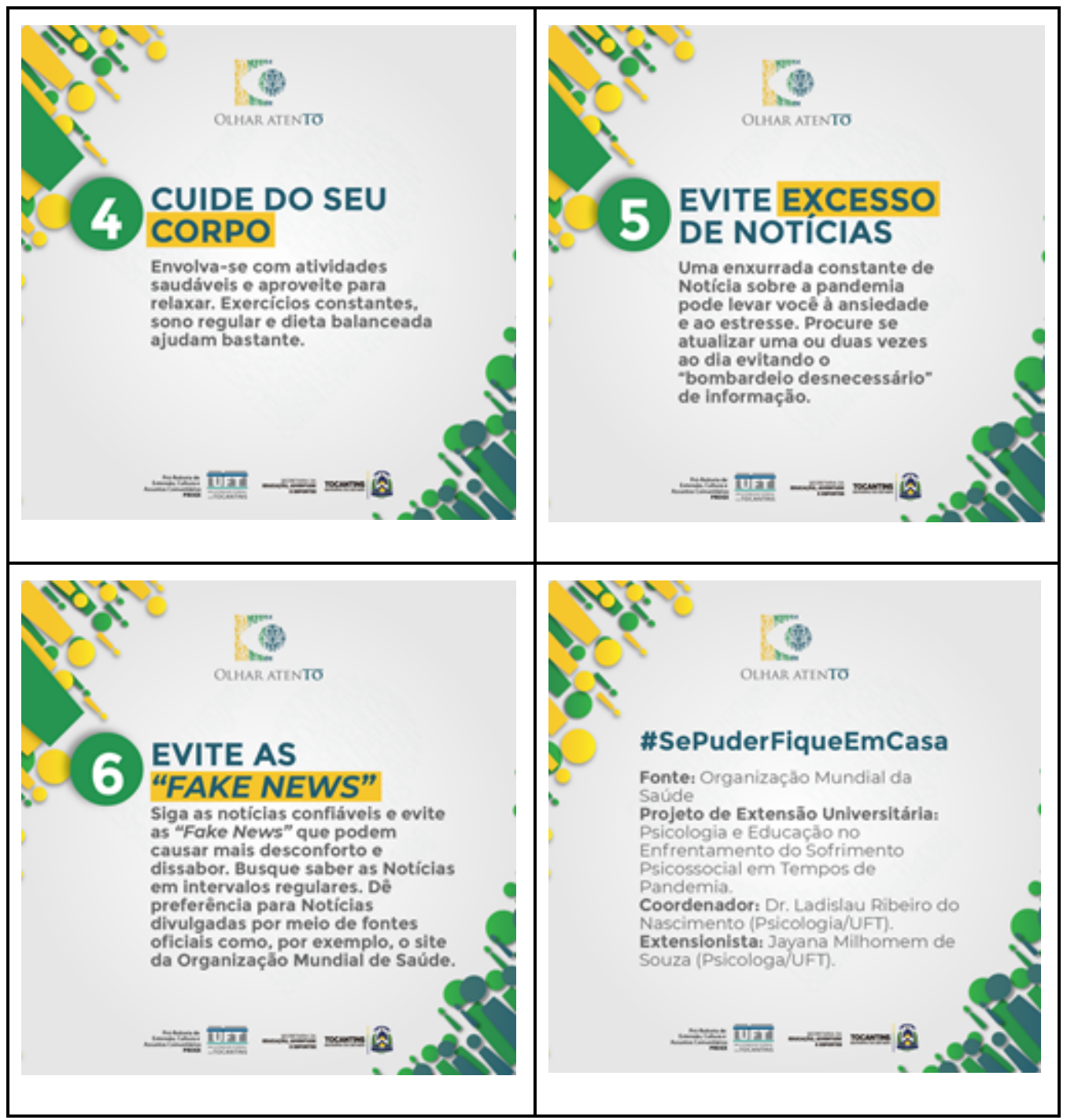

Elaborado pelos autores. 


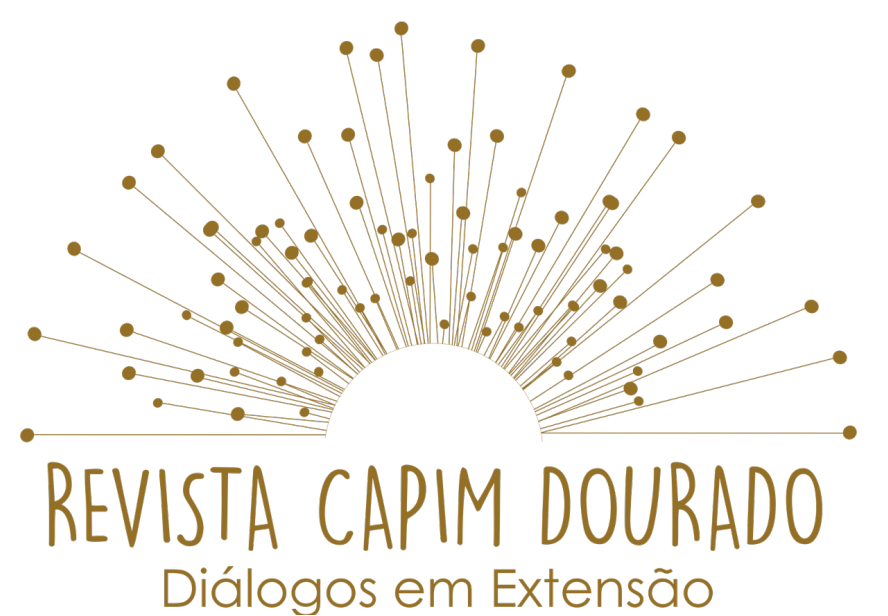

ISSN n² 2595-7341

Vol. 3, n. 2, Maio-Agosto, 2020

DOI: http://dx.doi.org/10.20873/uft.2595-7341.2020v3n2p47

As informações foram extraídas das recomendações da Organização Mundial da Saúde (OMS, 2020) e das cartilhas publicadas pela Fundação Oswaldo Cruz como material de apoio ao desenvolvimento de ações nos campos de Saúde Mental e Atenção Psicossocial na pandemia Covid-19 (BRASIL, 2020a), e tiveram como objetivos: orientar o público sobre como proteger a saúde mental e enfrentar o sofrimento psicossocial em tempos de pandemia.

\section{Atividades de intervenção psicossocial}

A primeira atividade de abordagem psicossocial foi realizada por meio da plataforma Google Meet. A ação teve como público-alvo um grupo de 23 professores, duas orientadoras pedagógicas e uma diretora de um centro de ensino médio situado em Miracema do Tocantins. O encontro teve como principal objetivo acolher os professores em um espaço formativo pensado para preparar a equipe docente que retomará as atividades de ensino na semana seguinte. No que se refere às mudanças na forma de lecionar, em um primeiro momento, professores da equipe ministraram aulas através da plataforma Google Meet. No mês seguinte, retornaram parcialmente para as atividades de ensino no modo presencial, de acordo com o plano de retorno às aulas proposto pela SEDUC-TO (PORTAL SEDUC, 2020).

A intervenção psicossocial teve início a partir do acolhimento feito pela diretora da escola. Em seguida, a extensionista e o coordenador se apresentaram para a equipe introduziram o tema proposto para o encontro, a saber: efeitos psicossociais da pandemia e possíveis estratégias para o enfrentamento do sofrimento psicossocial. 


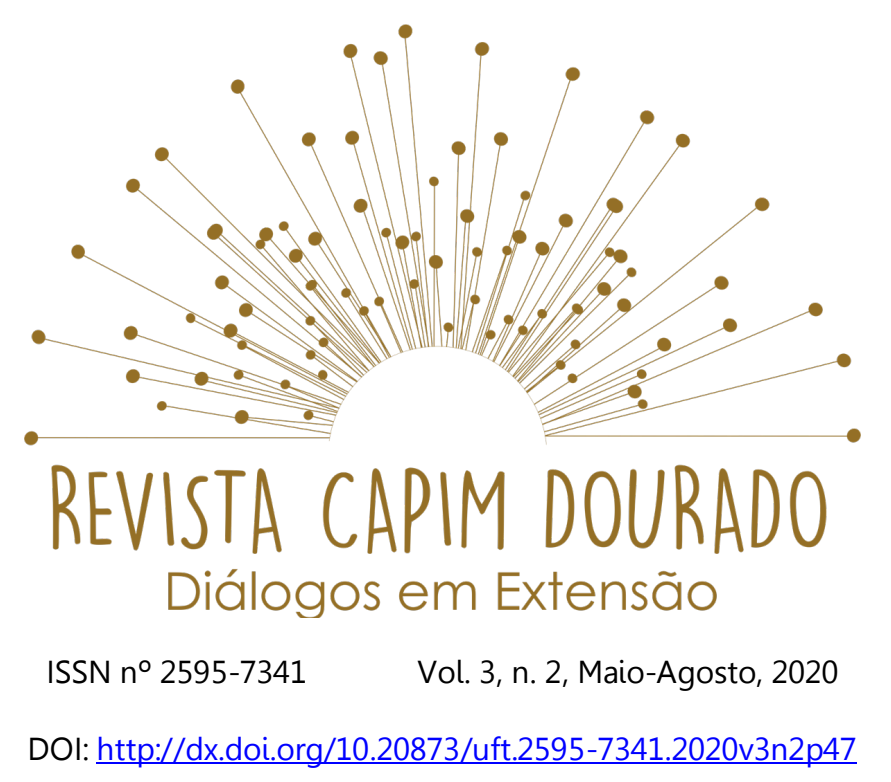

Discorremos sobre a importância de professoras e professores reservarem um espaço em suas respectivas casas para a realização do trabalho remoto. $\mathrm{Na}$ mesma perspectiva, discorremos sobre a dinâmica das identidades na relação indivíduo-trabalho (NASCIMENTO; MALVEZZI, 2015) e apontamos para a necessidade de negociarem com seus familiares a criação de limites ao desempenho de seus papéis profissionais naqueles espaços até então reservados para o desempenho de outros papéis, tais como o papel de filho, ou o papel de esposa, apenas para citar dois exemplos.

Mencionamos o fato de as pessoas vivenciarem mudanças decorrentes do distanciamento social, bem como aquelas associadas com o uso de Tecnologias da Informação e Comunicação (TIC) para o exercício da prática docente de maneiras distintas, especialmente em virtude de diferenças no que diz respeito às necessidades individuais (BAUMEISTER, 1991) e até mesmo ao tipo psicológico (CASADO, 1993) de cada um.

Discorremos sobre manifestações psicológicas e psicossociais comuns neste contexto, tais como, medo, ansiedade, depressão, tristeza, irritabilidade, solidão e tédio. Na ocasião mencionamos o quanto o medo é fundamental para a adaptação e sobrevivência humana, pois impõe limites, porém, o medo produzido neste contexto de pandemia, pode se transformar em um medo patológico, pode se fundir em uma ansiedade, por exemplo, desenvolvendo assim uma psicopatologia (BRASIL, 2020b), foi orientado que se caso percebam que seus pensamentos e sentimentos estejam persistentes e intensos ao longo do tempo, assim como com risco de complicações, a melhor saída pode ser a 


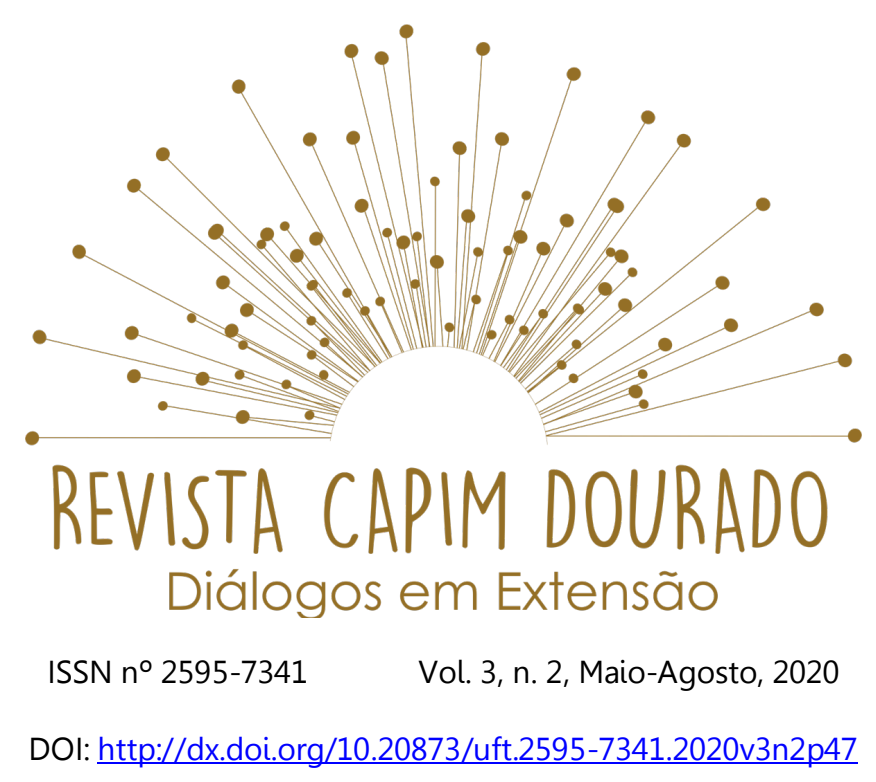

busca pelo apoio de um profissional psicólogo ou psiquiatra para cuidados específicos.

Em seguida, compartilhamos informações para o manejo do sofrimento psicossocial e à promoção do bem-estar, tendo como principais referências as recomendações divulgadas pela Organização Mundial da Saúde (OMS, 2020) e os materiais de apoio ao desenvolvimento de ações nos campos de Saúde Mental e Atenção Psicossocial publicados pela Fundação Oswaldo Cruz (BRASIL, 2020a; BRASIL, 2020b). As recomendações sugerem preservação de vínculos e laços com amigos, colegas e familiares, estabelecimento de rotinas adequadas às restrições do momento, e investimento em práticas de autocuidado e de responsabilidade social.

Falamos também sobre a importância de cada pessoa realizar atividades prazerosas e/ou experimentar outras formas de expressão, tais como a dança, pintura, desenho, música e/ou escrita. Cuidar do corpo, sem se expor em ambientes de risco, envolvendo-se em atividades saudáveis, como exercícios físicos, sono regular e uma dieta balanceada, evitando o uso abusivo de álcool e outras drogas. Evitar excesso de notícias sobre a pandemia e ter cuidado com informações falsas; neste momento é importante filtrar as informações, pois o excesso de notícias pode levar a ansiedade e ao estresse, para isso recomendamos atualizar-se uma ou duas vezes ao dia e priorizar o acesso a fontes confiáveis, como site oficial da OMS.

Apontamos para a necessidade de as pessoas apegarem-se aos fatos, ao invés de se deixar influenciar pelos rumores. Para tanto, o cuidado na escolha dos 


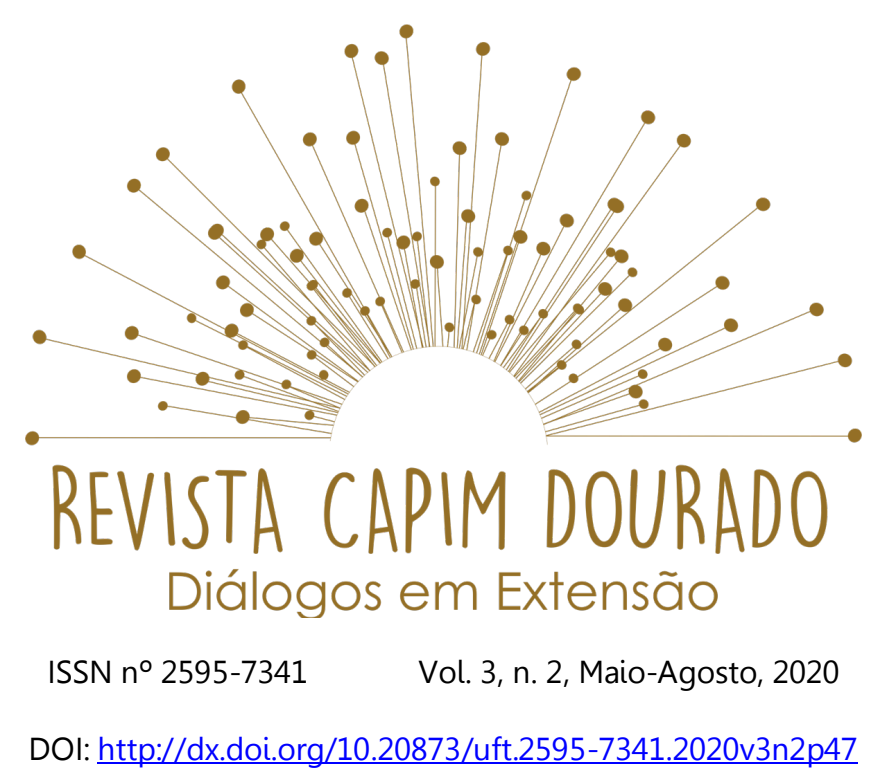

canais de comunicação utilizados para se informar acerca da pandemia seria a melhor alternativa.

Sugerimos o resgate através da memória das estratégias utilizadas para o alcance de estabilidade emocional em eventuais experiências de crise vivenciadas em outros momentos da vida; ou seja, o que se fazia antes da pandemia para ter uma sensação de calma, tranquilidade, conforto e autocuidado poderia ser aplicado no contexto atual, uma vez que, recursos e estratégias que foram eficazes em determinado momento podem ser utilizados em outras situações de crise. Dentre as atividades com potencial promover estabilidade emocional, sugerimos: meditação, reza/oração, música, filme, leitura, escrita. Aproveitamos para falar sobre a importância de as pessoas reservarem ao menos oito horas para o sono.

Na ocasião abrimos para a participação dos professores por meio da fala, já que estes já vinham comentando de forma escrita no chat da plataforma usada; como facilitador foi sugerido pensar e identificar qual(is) principal(is) sentimento(s) experimentado ao longo deste período de pandemia. $O$ sentimento mais mencionado foi o medo, do novo, do início das aulas, medo de perder entes querido, medo dos filhos e familiares contrair o vírus. Sentimentos como ansiedade, preocupação, inquietação, tristeza e insegurança também foram bastante citados, por outro lado, apenas uma participante mencionou está tranquila.

Buscamos ao máximo transmitir confiança e tornar aquele ambiente seguro para acolher as demandas dos participantes, e podemos dizer que isso foi possível, tendo em vista que algumas professoras relataram experiências 


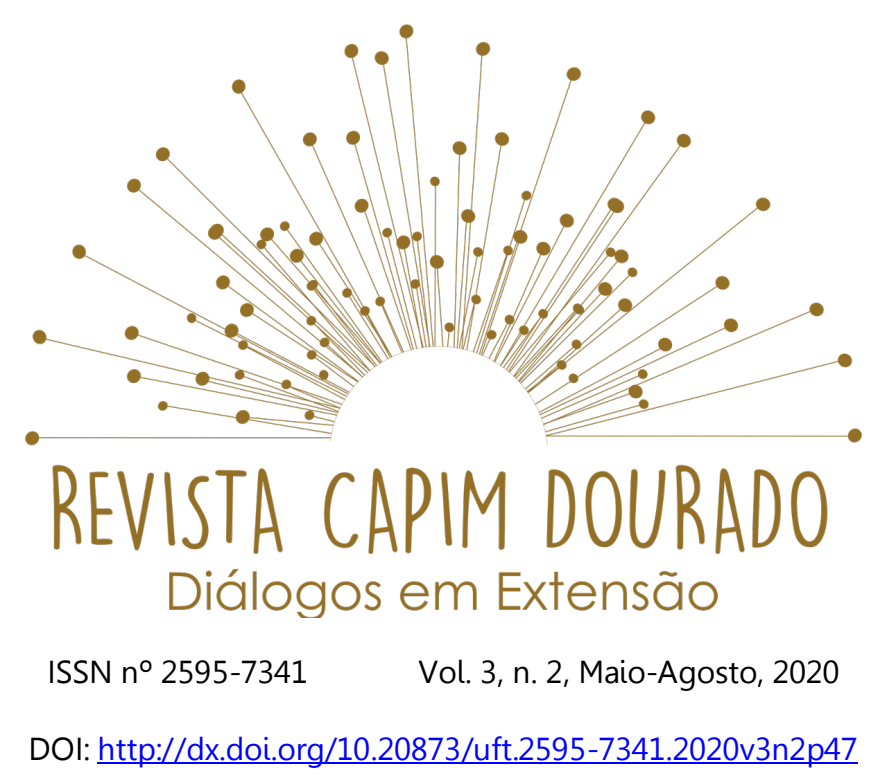

marcantes, como, o caso de uma que mencionou ter perdido três parentes vítimas de coronavírus e no momento seu pai se encontrava com Covid-19 e por isso ela estava com muito medo e não saia de casa. Outra também relatou que seu primo estava internado, usando respirador, compartilhando assim do mesmo sentimento de tristeza e medo. Em alguns momentos, foi possível observar algumas participantes chorando e com a voz embargada ao falar.

O encontro teve duração de duas horas e ao final recebemos um feedback positivo dos participantes. "Este momento é muito rico para nós... Parabéns por nos proporcionar este espaço para troca e crescimento", comentou uma participante. "Momento rico para a atual conjuntura", "Muito Obrigado por suas contribuições, certamente será de grande valia para nossas vidas e pra esse momento que estamos vivendo!" mencionaram outros. Os agradecimentos se estenderam até o final, além de manifestarem interesse por outros encontros como este.

A segunda atividade, assim como a primeira, foi realizada por meio da plataforma Google Meet, desta vez teve como público-alvo as orientadoras e os orientadores educacionais do estado do Tocantins, convidadas por meio do programa Olhar Atento. A ação envolveu a participação de mais de 400 pessoas, divididas em dois grupos, sendo que o primeiro grupo contou com 209 participantes das regionais de Araguaína, Araguatins, Tocantinópolis, Colinas, Pedro Afonso, Guaraí e Miracema. Já no segundo grupo participaram 207 orientadores das regionais de Gurupi, Porto Nacional, Palmas, Paraíso, Dianópolis e Arraias. 


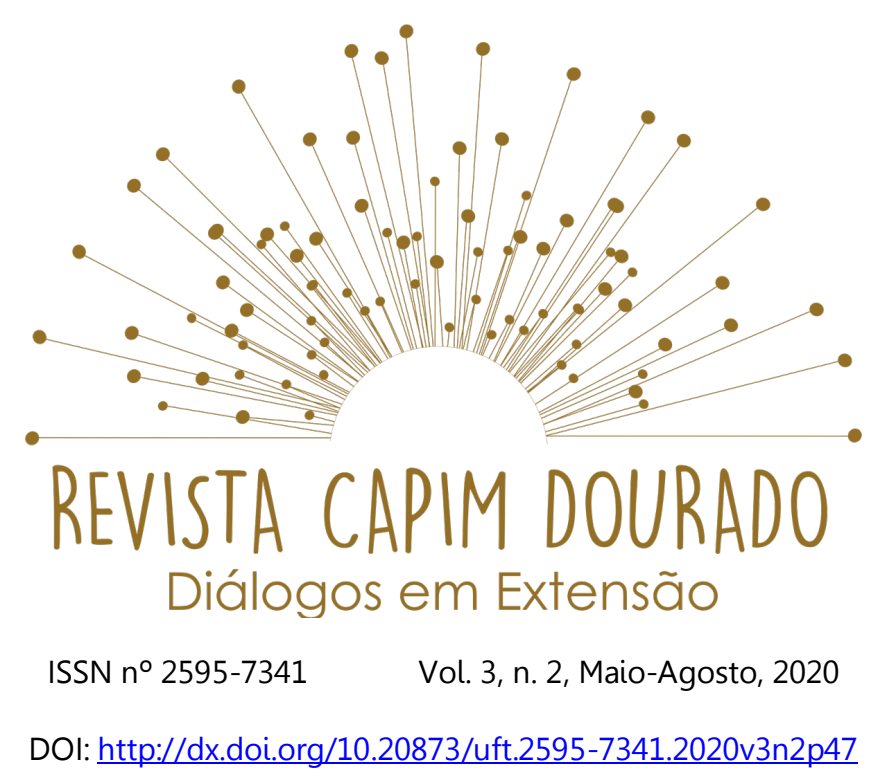

As intervenções psicossociais ocorreram em dois momentos com os dois grupos diferentes, ambos com a finalidade de prestar acolhimento inicial ao público-alvo e divulgar ações futuras do Programa Olhar Atento, por meio da SEDUC-TO. Os dois momentos foram iniciados com a fala da superintendente da SEDUC-TO, seguida pelo coordenador que se apresentou e fez uma breve explanação do projeto de extensão, enfatizando os objetivos e metodologia da ação; e apresentação da extensionista.

Destinamos uma hora para cada encontro e buscamos sermos democráticos quanto aos assuntos debatidos, tentando ao máximo contemplar os dois grupos com as mesmas informações; como as recomendações para a promoção do bem-estar e manejo do sofrimento psicossocial em tempos de pandemia, divulgadas pela OMS (2020), assim como aludimos sobre as reações e manifestações psicossociais mais frequentes e esperadas neste momento, e as estratégias de cuidado psíquico em situação de pandemia (BRASIL, 2020a).

Aberto ao público-alvo, no primeiro grupo uma orientadora mencionou o quanto sente saudades de abraçar, pois segundo ela a aproximação é considerada a "marca" dos orientadores educacionais, ainda comentou sua aflição em relação à volta as aulas e não poder abraçar os alunos. Outra participante interrogou se a pandemia tem mesmo o poder de causar psicopatologias ou é apenas um momento propício para desenvolvê-las. O coordenador respondeu que o problema não é o vírus em si, mas a vulnerabilidade de alguns grupos, utilizando-se do livro "A cruel pedagogia do vírus", escrito por Boaventura de Sousa Santos (2020), faz uma reflexão de que alguns coletivos sociais têm em comum padecerem de vulnerabilidades e 


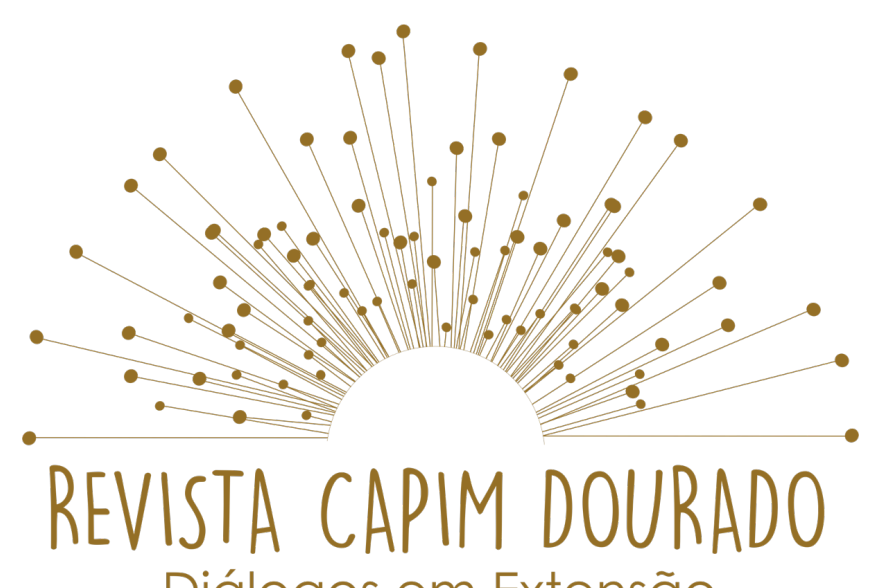

\section{Diálogos em Extensão}

ISSN n 2595-7341 Vol. 3, n. 2, Maio-Agosto, 2020

DOI: http://dx.doi.org/10.20873/uft.2595-7341.2020v3n2p47

fragilidades que precedem a pandemia e se agravam com ela, a saber, as mulheres, trabalhadores informais, precários, da rua e os ditos autônomos, as pessoas sem abrigo ou em situação de rua, moradores de periferias pobres, internados, deficientes, idosos, entre outros (SANTOS, 2020).

Nitidamente emocionada, uma orientadora desabafou sua preocupação com os alunos e seus familiares neste momento de pandemia, demonstrando grande sensibilidade com os desdobramentos possíveis do distanciamento social na vida dos seus orientandos e finaliza questionando "longe das escolas o que pode ter acontecido com os alunos durante todo esse tempo?", empático o coordenador acolhe esta orientadora e diz não ser possível saber o que está acontecendo ou aconteceu com cada um, essa pergunta só terá resposta no póspandemia, e fortalecer os laços de solidariedade e a rede de apoio é importante para se preparar para este retorno.

Finalizamos o primeiro encontro com a fala do Diretor de Gestão da SEDUC-TO que se apresentou e retomou alguns pontos do diálogo que se estendeu até ali, e fazendo uma analogia com o programa, mencionou a importância do "olhar atento" que os educadores devem ter com os alunos e familiares neste momento, mesmo a distância, assim como com seus pares, pois espaços como este são justamente para um fortalecer e cuidar do outro.

O segundo grupo mostrou tanto interesse quanto o primeiro em falar, questionar e desabafar suas inquietações e angústias relacionadas ao momento atual, porém não houve tempo suficiente para que todos falassem. Das suas preocupações podemos mencionar a vulnerabilidade social de alguns alunos, 


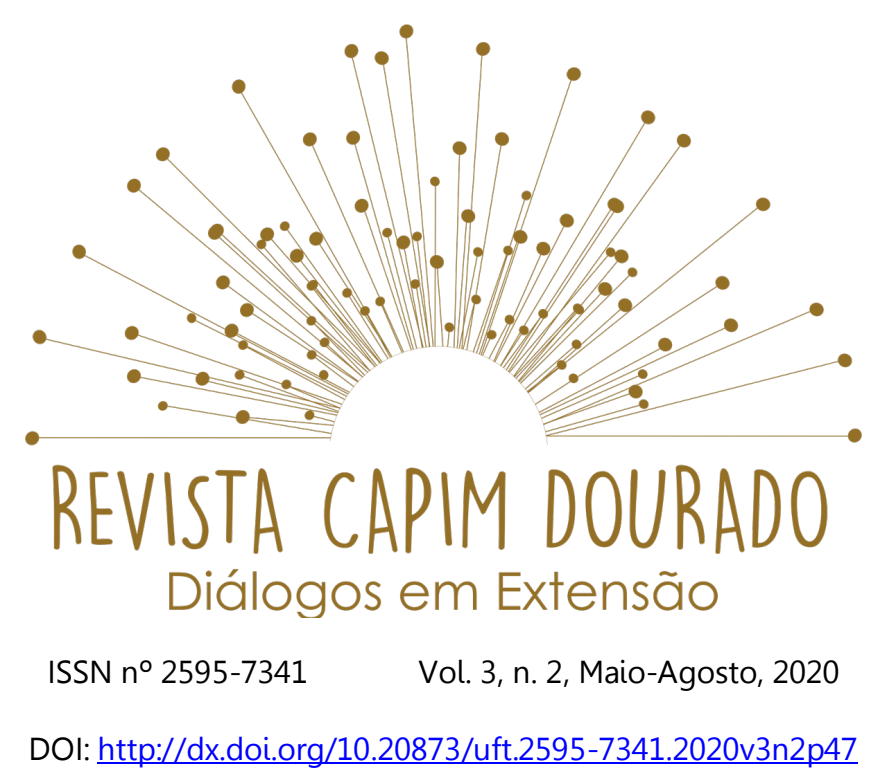

inclusive a falta de internet e meios de acessar as aulas online, a falta de apoio familiar e a violência doméstica.

\section{RESULTADOS E DISCUSSÃO}

A live promovida pelo programa Olhar Atento foi o evento de lançamento do projeto de extensão, teve a finalidade de apresentar a ação e divulgar a parceria entre a PROEX/UFT e a SEDUC-TO. Este momento não permitiu a participação ativa (JACQUES, M.G.C. et al, 1998) dos sujeitos envolvidos, porém mobilizou provocações e permitiu que alguns profissionais interessados entrassem em contato com o coordenador, possibilitando assim novos eventos.

Durante o encontro com os professores do centro de ensino médio de Miracema-TO, os participantes se expressaram abertamente, expondo suas angústias e dificuldades enfrentadas no momento. Pudemos notar a existência de vínculo afetivo e sentimento de pertença no grupo, tendo em vista que um sustenta e acolhe o outro sempre que necessário; e nós fomos apenas facilitadores dessas trocas.

Os participantes puderam externalizar seus sentimentos, deixando evidentes suas emoções, e nessa experiência perceberam que seus pares estão passando por situações e inquietações semelhantes, e este certamente é um benefício de trabalhar com um grupo, pois permite reconhecer os sentimentos compartilhados e potencializar formas de enfrentamento de maneira conjunta.

O contato com os orientadores educacionais, além de contribuir para o fortalecimento subjetivo do público-alvo em um momento totalmente inédito na 


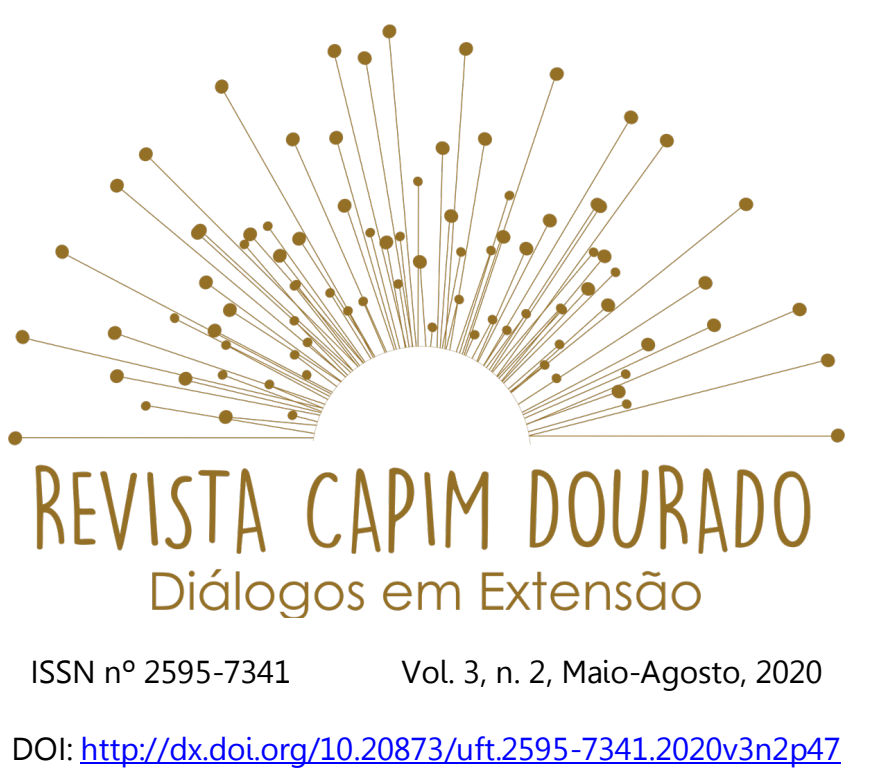

história atual; abriram espaço de escuta e circulação da palavra, permitindo (re)construir e (re)significar a situação por meio da fala.

\section{CONSIDERAÇÕES FINAIS}

A incerteza e as mudanças geradas neste contexto de pandemia recaem sobre as pessoas de diferentes maneiras. A variação na resposta diante das modificações impostas pela Covid-19 no Brasil tem relação com fatores como: desigualdade social, faixa etária, escolaridade, crenças, gênero, origem étnicoracial dentre outros marcadores de diferença. Todavia, de um modo geral, podese dizer que a pandemia tem produzido medo, preocupação, mudanças de hábitos alimentares, alterações no sono, uso e abuso de álcool, cigarro e outras drogas.

Muitas pessoas temem o desemprego, a falência, ou a morte de familiares e a própria morte. Há quem evite buscar apoio especializado em unidades de saúde pelo medo de eventual contágio naqueles contextos. Há também temores em relação à prováveis processos de exclusão e de estigmatização em decorrência do histórico de infecção. Enquanto há quem sofra com medo de perder entes queridos em função da letalidade do vírus (OMS, 2020).

Diante desta realidade, por meio de uma intervenção ampliada, de abordagem integrada, o projeto foi efetivado como uma tecnologia social (TS) voltada para a emancipação do público-alvo (RODRIGUES; BARBIERI, 2008). Projetou-se a criação e a aplicação de uma TS capaz de abranger o sofrimento psicossocial acarretado pela incerteza e pelas inúmeras rupturas provocadas pela 


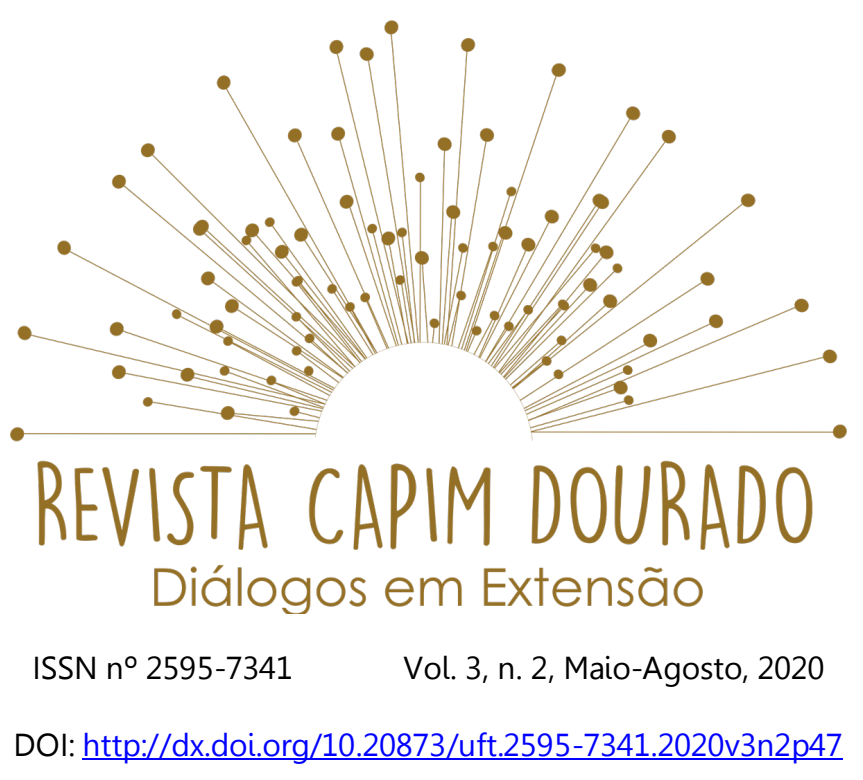

crise pandêmica. Vale salientar que, TS difere-se de tecnologia convencional ao promover inclusão social, engajamento e emancipação social, ao invés de visar exclusivamente o lucro e de "[...] provocar a exclusão social" (DAGNINO, 2013, p. 253).

Assim, realizou-se uma prática de Extensão Universitária apoiada na articulação entre saberes e fazeres da psicologia na interface com a educação. Buscou-se o alcance dos objetivos sob um enfoque ético, capaz de promover cidadania e de fortalecer a democracia por meio de inclusão e empoderamento de uma população vulnerável e carente de acesso aos serviços psicológicos.

\section{REFERÊNCIAS:}

BRASIL. Ministério da Saúde. Fundação Oswaldo Cruz. Centro de Estudos e Pesquisas em Emergências e Desastres em Saúde (CEPEDES/Fiocruz). Saúde Mental e Atenção Psicossocial na Pandemia COVID-19. Recomendações Gerais. Brasília, 2020a. Disponível em < https://www.fiocruzbrasilia.fiocruz.br/wpcontent/uploads/2020/04/Sa\%C3\%BAde-Mental-e-Aten\%C3\%A7\%C3\%A3o-

Psicossocial-na-Pandemia-Covid-19-recomenda\%C3\%A7\%C3\%B5es-

gerais.pdf > Acesso em 18 de Junho de 2020.

BRASIL. Ministério da Saúde. Fundação Oswaldo Cruz. Centro de Estudos e Pesquisas em Emergências e Desastres em Saúde (CEPEDES/Fiocruz). Saúde Mental e Atenção Psicossocial na Pandemia COVID-19: Recomendações para Gestores. Brasília, 2020b. Disponível em < https://www.arca.fiocruz.br/handle/icict/41030>Acesso em 20 de Junho de 2020. 


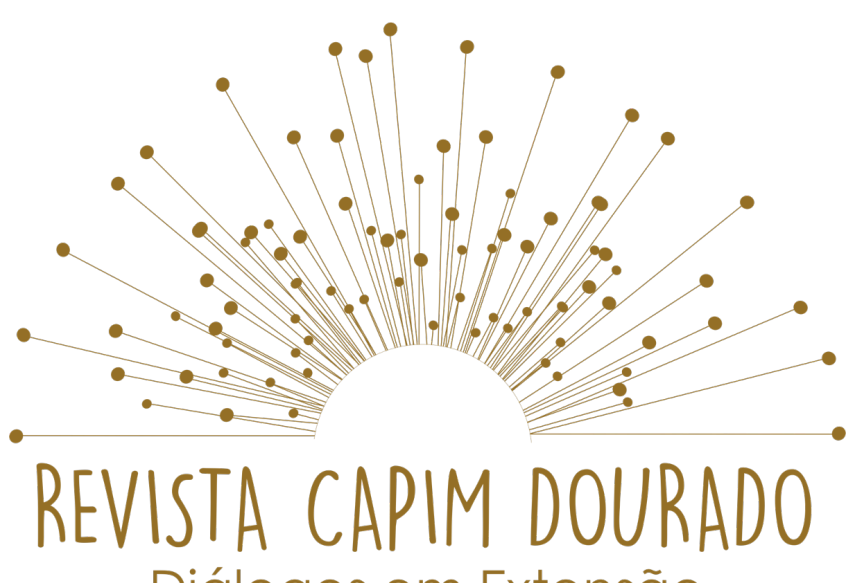

Diálogos em Extensão

ISSN n 2595-7341 Vol. 3, n. 2, Maio-Agosto, 2020

DOI: http://dx.doi.org/10.20873/uft.2595-7341.2020v3n2p47

BAUMEISTER, R. F. Meanings of life. Guilford press, 1991.

CASADO, T. Tipos psicológicos e estilos de comportamento motivacional: o diálogo entre Jung e Fromm. 1993. Tese de Doutorado. Dissertação (Mestrado)Faculdade de Economia, Administração e Contabilidade da Universidade de São Paulo. São Paulo, FEA USP.

DAGNINO, R. O envolvimento da FBB com políticas públicas em tecnologia social: mais um momento de viragem. Tecnologia Social e Políticas Públicas. São Paulo: Instituto Pólis, 2013.

DUAN, Li; ZHU, Gang. Psychological interventions for people affected by the COVID-19 epidemic. The Lancet Psychiatry, v. 7, n. 4, p. 300-302, 2020. Disponível em < http://doi.org/10.1016/S2215-0366(20)30073-0> Acesso em 15 de Maio de 2020.

IASC Reference Group on Mental Health and Psychosocial Support in Emergency Settings Interim Briefing Note: ADDRESSING MENTAL HEALTH AND PSYCHOSOCIAL ASPECTS OF COVID-19 OUTBREAK Version 1.5 February 2020 Disponível em< 03/IASC\%20Interim\%20Briefing\%20Note\%20on\%20COVID19\%200utbreak\%20Readiness\%20and\%20Response\%200perations\%20\%20MHPSS 0.pdf> Acesso em 14 de Junho de 2020. 


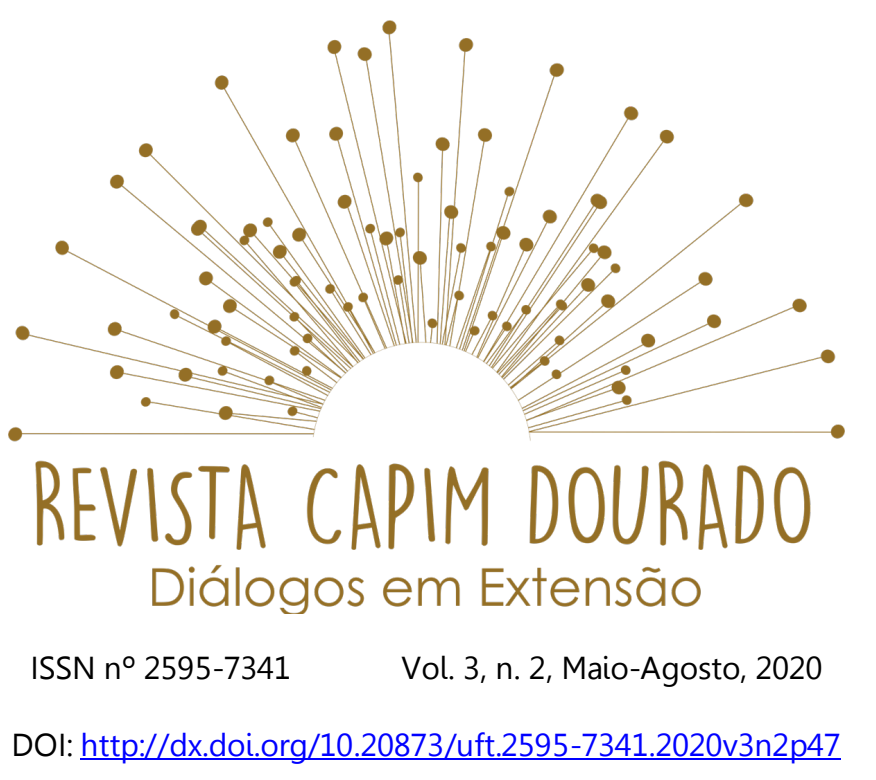

GANDARA, G. Governo do Tocantins lança Programa Olhar Atento destinado ao bem-estar de educadores e estudantes da rede estadual. Portal Tocantins. Palmas, 16 de Jun. de 2020. Edição: Thâmara Cruvinel. Disponível em: $<$ https://portal.to.gov.br/noticia/2020/6/16/governo-do-tocantins-lancaprograma-olhar-atento-destinado-ao-bem-estar-de-educadores-e-estudantesda-rede-estadual/>. Acesso em: 24 de Jun. de 2020.

JACQUES, M.G.C et al. Psicologia Social Contemporânea. Petrópolis, RJ: Vozes, 1998.

MOTA, N.D. Rede estadual de ensino inicia atividades não presenciais nesta segunda-feira, 29. Portal da SEDUC-TO. Palmas, 26 de Jun. de 2020. Disponível em: $<$ https://seduc.to.gov.br/noticia/2020/6/26/rede-estadual-de-ensino-iniciaatividades-nao-presenciais-nesta-segunda-feira-29/> Acesso em: 30 de Jun. de 2020.

NASCIMENTO, L. R; MALVEZZI, S. Identity: an instrument for mergers and acquisitions. In: Advances in mergers and acquisitions. Emerald Group Publishing Limited, 2015. Disponível em: < https://www.emerald.com/insight/content/doi/10.1108/S1479361X20150000014008/full/html?utm source=TrendMD\&utm medium=cpc\&ut m campaign=Advances in Mergers \%2526 Acquisitions TrendMD $1>$ Acesso em 15 de Junho de 2020. 


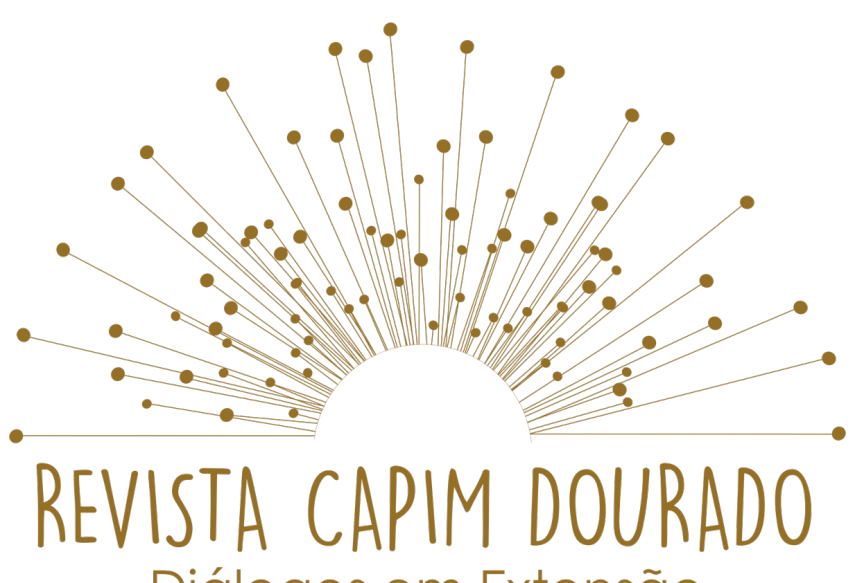

\section{Diálogos em Extensão}

ISSN n² 2595-7341

Vol. 3, n. 2, Maio-Agosto, 2020

DOI: http://dx.doi.org/10.20873/uft.2595-7341.2020v3n2p47

NEIVA, K. M. C. Intervenção psicossocial: aspectos teóricos, metodológicos e experiências práticas. Editora: Vetor, 2010.

RODRIGUES, I.; BARBIERI, J. C. A emergência da tecnologia social: revisitando o movimento da tecnologia apropriada como estratégia de desenvolvimento sustentável. Revista de Administração Pública, v. 42, n. 6, p. 1069-1094, 2008.

SANTOS, B.S. A cruel pedagogia do vírus. Ed. Almedina. 2020. Disponível em: $<$ https://www.cpalsocial.org/documentos/927.pdf>. Acesso em: 30 de Jun. de 2020.

VYGOTSKY, L. S. Linguagem, desenvolvimento, aprendizagem. Ed. Scone, 1988.

WANG, C et al. Immediate psychological responses and associated factors during the initial stage of the 2019 coronavirus disease (COVID-19) epidemic among the general population in China. International journal of environmental research and public health, v. 17, n. 5, p. 1729, 2020. Disponível em $<$ https://www.ncbi.nlm.nih.gov/pubmed/32155789> Acesso em 22 de Abril de 2020.

WORLD HEALTH ORGANIZATION et al. Mental health and psychosocial considerations during the COVID-19 outbreak, 18 March 2020. World Health Organization, 2020.

XIAO, Chunfeng. A novel approach of consultation on 2019 novel coronavirus (COVID-19)-related psychological and mental problems: structured letter 


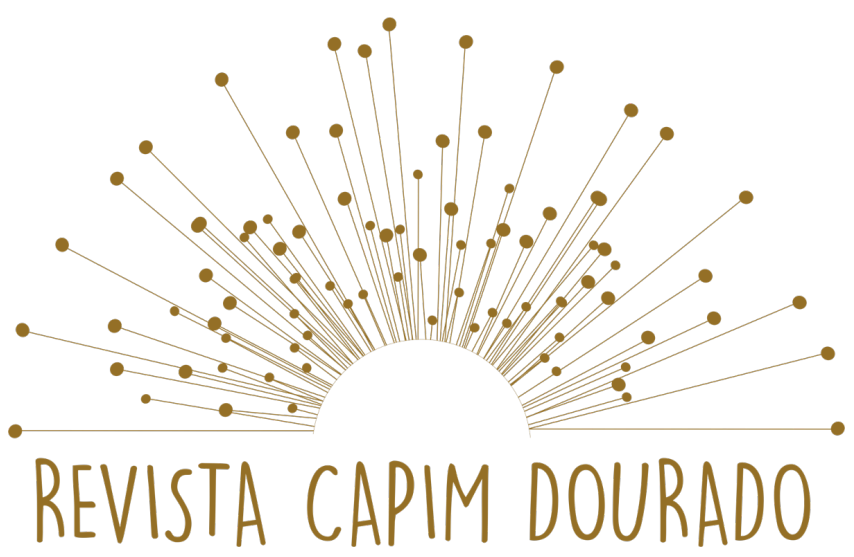

Diálogos em Extensão

ISSN n 2595-7341 Vol. 3, n. 2, Maio-Agosto, 2020

DOI: http://dx.doi.org/10.20873/uft.2595-7341.2020v3n2p47

therapy. Psychiatry Investigation, v. 17, n. 2, p. 175, 2020. Disponível em <https://www.ncbi.nlm.nih.gov/pubmed/32093461> Acesso em: 28 de Maio de 2020. 